\title{
Development of early maturity maize hybrids for resistance to Fusarium and Aspergillus ear rots and their associated mycotoxins
}

\author{
L. Stagnati ${ }^{1}$, M. Martino ${ }^{1}$, P. Battilani ${ }^{1}$, M. Busconi ${ }^{1,2}$, A. Lanubile ${ }^{1,2^{*}}$ and A. Marocco ${ }^{1,2^{*}}$ \\ ${ }^{1}$ Department of Sustainable Crop Production, Università Cattolica del Sacro Cuore, Via E. Parmense, 84, 29122, Piacenza, \\ Italy; ${ }^{2}$ Research Centre for Biodiversity and Ancient DNA, Università Cattolica del Sacro Cuore, Via E. Parmense, 84, \\ 29122, Piacenza, Italy; alessandra.lanubile@unicatt.it; adriano.marocco@unicatt.it
}

Received: 20 December 2019 / Accepted: 17 April 2020

(c) 2020 Wageningen Academic Publishers

OPEN ACCESS CC) R(요 RESEARCH ARTICLE

\begin{abstract}
Maize is mainly affected by two fungal pathogens, Fusarium verticillioides and Aspergillus flavus, causing Fusarium ear rot (FER) and Aspergillus ear rot (AER), respectively. Both fungi are of concern to stakeholders as they affect crop yield and quality, contaminating maize grains with the mycotoxins fumonisins and aflatoxins. The easiest strategy to prevent pre-harvest contamination by F. verticillioides and A. flavus is to develop maize hybrids resistant to FER and AER, as well as to their associated mycotoxins. The objective of this investigation was to test $46 \mathrm{~F}_{1}$ hybrids, originated from different Italian, US and Canadian breeding groups, for these important traits and their agronomic performances. All hybrids were planted and artificially inoculated with toxigenic strains of $F$. verticillioides and $A$. flavus at two locations in 2017, and the best performing 17 out of 46 were also tested in 2018. Ear rots were present in all hybrids in 2017 and 2018, with percentages ranging from 6.50 to 49.50\%, and 5.50 to 45.53\%, for FER and AER, respectively. Seven hybrids (PC8, PC15, PC9, PC11, PC14, PC34 and PC17) presented the lowest levels of both diseases considering the overall locations and growing seasons, and three of these (PC8, PC11 and PC14) were also amongst the least mycotoxin contaminated hybrids in 2017. The inbred lines used in hybrid production may provide additional sources of resistance suitable in breeding programs targeting multiple pathogens and their mycotoxins.
\end{abstract}

Keywords: Fusarium ear rot, Aspergillus ear rot, resistance, mycotoxins, grain yield, maize hybrids

\section{Introduction}

Maize (Zea mays L.) is the most cultivated cereal grain in the world for yield and second for cultivated area (FAO, 2018). This cereal is a staple crop in Africa and in developing countries, while in developed ones is used mainly to feed livestock and for energy purposes. It is reported that in the near future the consumption of cereals will increase driven by an improved demand of cereals for animal feeding, which relies for $70 \%$ on maize (FAO, 2017).

Maize is affected by numerous fungal pathogens colonizing developing kernels and ears and causing ear rots. Many of these fungi are able to produce toxic secondary metabolites, known as mycotoxins that affect the quality and marketability of grains (Lanubile et al., 2017a; Marin et al., 2013; Morales et al., 2018). Among these fungi, two of the most relevant are Fusarium verticillioides and Aspergillus flavus. F. verticillioides (Sacc.) Nirenberg (synonym Fusarium moniliforme Sheldon, teleomorph Gibberella moniliformis Wineland) is the causal agent of stalk rot and Fusarium ear rot (FER) in maize, which can be found almost in all maize fields at harvest especially in humid and temperate climates nonetheless in tropical and subtropical countries (Lanubile et al., 2017a; Morales et al., 2018). A. flavus, the causal agent of Aspergillus ear rot (AER), is mainly a saprophyte and maize can be severely affected both in the field and during storage resulting in severe rotting of kernels and ears. The occurrence of AER is primarily in regions characterised by hot and dry climates (Lanubile et al., 2014a) and is a main concern in Africa (Okoth et al., 2017). 
The presence of these two fungi in maize fields results in the contamination of the grain with mycotoxins. $F$. verticillioides is able to produce several toxins, such as moniliformins, fusarins and fumonisins, where the most relevant is fumonisin $\mathrm{B}_{1}$, while $A$. flavus produces aflatoxins (Desjardins and Proctor, 2007; Marin et al., 2013). From a toxicological perspective these mycotoxins are carcinogenic compounds responsible of acute and chronic disorders both in humans and animals (Lanubile et al., 2014a, 2017a; Marin et al., 2013; Okoth et al., 2017; Szabo et al., 2018; Warburton et al., 2013).

An efficient solution to reduce ear rots and mycotoxin contamination is the development of host resistance, preferably in locally-adapted breeding materials. However, maize hybrids grown currently have insufficient resistance levels (Warburton et al., 2013; Zila et al., 2013). Many studies have focused on the research of resistance genetic markers for ear rot diseases (Gaikpa and Miedaner, 2019; Maschietto et al., 2017; Robertson et al., 2006; Warburton et al., 2013; Zila et al., 2013, 2014), in the selection of resistant inbred (Lanubile et al., 2010; Reid et al., 2009), in the development of adequate phenotyping techniques (Chungu et al., 1996; Ju et al., 2017; King and Scott, 1982; Lanubile et al., 2014a; Septiani et al., 2019; Stagnati et al., 2019) and in the identification of low cost indicators of mycotoxin contamination (Morales et al., 2018).

With the purpose to evaluate hybrid performances, the present work focused on the development of 46 hybrids crossing inbred lines developed in different breeding programs for broad resistance against ear rots. All hybrids were evaluated for resistance to FER and AER, mycotoxin accumulation and agronomic performances in two locations in 2017, and the best performing 17 out of 46 were also tested in 2018. The results showed that seven hybrids (PC8, PC15, PC9, PC11, PC14, PC34 and PC17) presented the lowest levels of both FER and AER diseases considering the overall locations and growing seasons. Such genetic material may be useful for maize breeders to manage ear rot diseases and mycotoxin contamination.

\section{Materials and methods}

\section{Plant materials}

Forty-six $\mathrm{F}_{1}$ hybrids were produced and evaluated (Supplementary Table S1). Female lines used to produce $\mathrm{F}_{1}$ seeds were selected for their resistance to $F$. verticillioides and belong to different breeding experiments: twenty-four and nineteen $S_{5}$ and $S_{3}$ lines, respectively, and three $S_{7}$ Recombinant Inbred Lines (RIL).

\section{Selection of $\mathrm{S}_{5}$ female lines}

The breeding project to produce female inbred lines resistant to ear rots started by crossing 6 different Italian lines (named Lo) to 4 different US lines (Supplementary Table S1). Lines of US origin were selected as sources of resistance to mycotoxigenic fungi to improve the resistance level of Lo materials. Mp313E was developed in Mississippi from a direct self from Tuxpan and it was the first line released against $A$. flavus (Scott and Zummo, 1990); Mo18W was released in 1960s, from the cross of WF9 $\times$ Mo22, as resistant to A. flavus (Zuber, 1973); the inbred Mp420 was released as a source of resistance to kernel infection by $A$. flavus and it was developed by selfing within a cross between the inbred $\mathrm{Mp} 1$ and an $\mathrm{S}_{3}$ line from the open pollinated variety Hill Yellow Dent; Mp307 was developed as natural restorer of Texas cytoplasmic malesterility and as resistant genotype against $A$. flavus infection (https://npgsweb.ars-grin.gov). The $\mathrm{F}_{1}$ s between Lo and US lines were backcrossed (BC) to the female Lo parents. The resulting $\mathrm{BC}_{1} \mathrm{~F}_{1} \mathrm{~s}$ were selfed and the deriving $\mathrm{S}_{1}$ plants were self-pollinated and evaluated for plant morphology and flowering time. The $S_{2}$ families were grown ear-torow, evaluated for plant morphology and resistance to ear rots under natural conditions, and for each row, a single selfed-ear was harvested until the generation of $\mathrm{S}_{5}$-derived inbred lines was obtained.

\section{Selection of $S_{7}$ and $S_{3}$ female lines}

$\mathrm{S}_{7}$ female lines were derived from the cross of two lines having contrasting phenotypes for FER resistance: the resistant CO441, used as female, and the susceptible CO354, used as male. Both lines were achieved by the Eastern Cereal and Oilseed Research Centre, Agriculture and Agri-Food Canada (Ottawa, Canada) and maintained by sibling at the Department of Sustainable Crop Production in Piacenza (Italy). $188 \mathrm{~S}_{7}$ lines were developed and phenotypically evaluated for $F$. verticillioides resistance (Maschietto et al., 2017). From the cross of the resistant RIL 104 and 156, $19 \mathrm{~S}_{3}$ lines were selected based on plant morphology and resistance to artificial infection, according to Maschietto et al. (2017).

\section{Hybrid production}

$\mathrm{F}_{1} \mathrm{~s}$ hybrids were produced in Hijuela, San Francisco de Mostazal, Chile. For each hybrid to be produced, four rows of female line and two of male were planted. Rows were 5 $\mathrm{m}$ long, spaced $80 \mathrm{~cm}$ apart each row and $1 \mathrm{~m}$ aisle. Field trials were managed according to the standard agricultural practices followed in the area. Hybrids were produced by hand pollination. Female parents were crossed to one out of 3 different male inbred lines CO430, CO433 and CO441, according to their cycle length. The $\mathrm{CO} 430, \mathrm{CO} 433$ and CO441 were developed for resistance to three different 
fungal diseases Gibberella ear rot, FER and Common Smut, respectively (Reid et al., 2009). The list of the hybrids produced is reported in Supplementary Table S1. Commercial hybrids belonging to FAO maturity 400 and 500 classes were used as checks during 2017 [P1114 (500) and SUM405 (400)] and 2018 [Kefieros (500), SUM405 (400) and P003 (400)] growing seasons.

\section{Field experiments}

Field trials were set up during two years, 2017 and 2018, in two locations: San Zenone al Lambro (SZ) (45'19'23.84”N $-9^{\circ} 22^{\prime} 8.09^{\prime \prime} \mathrm{E}$, Milan, Italy) and Tribiano (T) $\left(45^{\circ} 24^{\prime} 31.63^{\prime \prime} \mathrm{N}\right.$ - 9'23'20.60”'E', Milan, Italy). In 2017, fields were sown on 4 and 7 April, while in 2018, on 27 April and 11 June for $\mathrm{SZ}$ and T, respectively. Each plot consisted of 4 rows $5 \mathrm{~m}$ long, spaced $80 \mathrm{~cm}$ apart each row and $1 \mathrm{~m}$ aisle. Three random replicates were planted for each hybrid in each location. Field trials were managed according to standard agricultural practices followed in the area. Harvesting data were 11 and 12 September in 2017 and 21 September and 30 October in 2018 for $\mathrm{SZ}$ and $\mathrm{T}$ locations, respectively.

Hybrids were phenotypically evaluated according to the UPOV protocol CPVO TP/2/3. Agronomic traits such as plants per row, lodged and smashed plants were taken on the central rows of the plots. Plant and ear heights were taken on five plants per plot, and ear/plant ratios were calculated. At harvesting, grain yield $(\mathrm{t} / \mathrm{ha}$ ) was recorded and reported to a final density of 7.2 plants $/ \mathrm{m}^{2}$; grain moisture (\%) was determined as well. Silk date was also recorded on every plot as the number of days between sowing and silk emergence on $50 \%$ of the plants in a plot.

\section{Inoculation, disease severity and mycotoxin evaluation}

The primary ear of 5 plants per plot was inoculated with a spore suspension of $F$. verticillioides MPVP 294. (Maschietto et al., 2017) and A. flavus MPVP A2092 (Lanubile et al., 2017b; Mauro et al., 2013), both originating from Italy. These strains are part of the culture collection of the Department of Sustainable Crop Production, Università Cattolica del Sacro Cuore of Piacenza, Italy. Inoculum for both strains was produced to a final concentration of $1 \times 10^{6}$ spores $/ \mathrm{ml}$. Ears were inoculated according to the pin-bar inoculation method at 15 DAP (days after pollination) (Lanubile et al., 2017a; Maschietto et al., 2017). Inoculated ears were harvested at maturity, and 5 additional ears were taken as non-inoculated controls.

Disease severity was evaluated on hand-harvested ears that were air dried in greenhouse. FER severity was visually evaluated, assessing the percentage of the rotted surface of the ear, using a 7 point severity grid and assigning 1 for the absence of infection, and numbers from 2 to 7 according to the percentage level of the infection, where $2=1-3 \%, 3=$
$4-10 \%, 4=11-25 \%, 5=26-50 \%, 6=51-75 \%$ and $7=76-100 \%$ (Maschietto et al., 2017). AER was evaluated by using an 11 point scale to assess the percentage of the rotted surface of the ear, scoring 0 for the absence of the infection and numbers from 1 to 10 according to the percentage level of the infection, where $1=1-10 \%, 2=11-20 \%, 3=21-30 \%$, $4=31-40 \%, 5=41-50 \%, 6=51-60 \%, 7=61-70 \%, 8=$ $71-80 \%, 9=81-90 \%$ and $10=91-100 \%$.

Mycotoxin analysis was carried out only on samples harvested and evaluated in 2017 growing season. Ears belonging to the same plot were bulked and shelled; a random sample of about 150-200 kernels was milled with a laboratory mill (CyclotecTM 1093 Sample Mill, FOSS) using a $1 \mathrm{~mm}$ mesh. Special attention was taken in the milling procedure avoiding cross-contamination of kernels showing different disease levels.

Mycotoxin contamination was evaluated using the VICAM Fumo-V AQUA and Afla-V AQUA strips (Watertown, MA, USA), a fluorometric-immunocapture assay, following manufacturer's protocol. Values of fumonisins $\left(\mathrm{B}_{1}+\mathrm{B}_{2}+\mathrm{B}_{3}\right)$ and aflatoxins $\left(B_{1}+B_{2}+G_{1}+G_{2}\right)$ given in the text are expressed in $\mu \mathrm{g} / \mathrm{kg}$.

\section{Selection of $F_{1}$ hybrids for the second year field trial}

After the first year of trials during 2017, $\mathrm{F}_{1}$ hybrids were selected according to the mean values of ear rot severity. A 99\% confidence interval was calculated using the Rmisc package (Hope, 2013) available in R software (R core team, 2017) based on the mean of the hybrids used in 2017 experiment. The limit to retain $\mathrm{F}_{1} \mathrm{~s}$ was $19 \%$ for FER and $17.4 \%$ for AER. $\mathrm{F}_{1} \mathrm{~s}$ having one or both values lower than the confidence limit were retained. Further selection was made discarding materials that were visually unsatisfactory. In Supplementary Table $\mathrm{S} 1$ the $17 \mathrm{~F}_{1}$ hybrids indicated in bold were evaluated during both growing seasons.

\section{Data analysis}

Data manipulation and visualisation was performed with $R$ software ( $R$ core team, 2017) and confidence intervals (CI) were calculated according to $\mathrm{CI}$ function $(\mathrm{CI}=0.95$; Hope, 2013). The average FER and AER scores of all the five inoculated ears in each plot was calculated. Box-Cox transformations of phenotypic data (Morales et al., 2018) were performed using the MASS package (Venables and Ripley, 2002) available in R. $\Lambda$ values for transformations were: 5.4 for days to silking, 0.2 for FER, 0.3 for AER, 0.5 for grain yield, -1.5 for grain moisture, 2 for plant height, 0.1 for ear height, -3.3 for lodged plant percentage and -0.5 for smashed plant percentage. For FER and AER under natural infection +1 constant was added to account for 0 before data transformation with $\lambda=-0.1$ (N-FER) and $\lambda=-$ 8.2 (N-AER). For lodged and smashed plant +1 constant 
was added during percentage computation to correct for 0 . Regarding fumonisins each sample was read three times and the mean of the three readings was computed. A 0.01 constant was added to account for 0 . Values were Box-Cox transformed $\lambda=0.311$. Aflatoxins were analysed only for hybrids that passed the ear rot threshold for the second year of cultivation in 2018. Each sample was read three times and a sample mean was subsequently calculated. A 0.01 constant was added to account for 0 . Values were Box-Cox transformed with $\lambda=0.3879$.

Correlation between traits were calculated. Two-ways ANOVA were conducted to test differences between hybrids and locations, with the exception of AER in San Zenone during 2018 (one-way ANOVA). Least Significance Difference (LSD) was calculated according to the LSD.test function available in the $\mathrm{R}$ package agricolae applying the Bonferroni correction (De Mendiburu, 2017).

\section{Results and discussion}

\section{Ear rots under artificial infection}

The present study examined the effects of artificial inoculation with $F$. verticillioides and $A$. flavus on different maize $F_{1}$ hybrids grown in San Zenone (SZ) and Tribiano (T) locations (North Italy) in 2017 and 2018, considering the severity of ear rot diseases, mycotoxin content and several agronomic traits. The full list of $46 \mathrm{~F}_{1}$ hybrids employed in this work is reported in Supplementary Table S1. In 2018, a subset of $17 \mathrm{~F}_{1}$ hybrids was further selected based on the highest grain yield values and lowest FER and AER incidence compared to the commercial hybrids used in 2017 experiment, and examined for the same traits reported before (Supplementary Table S1).

During the growing season 2017, the 46 maize $F_{1}$ hybrids evaluated at SZ and T differed significantly $(P \leq 0.001)$ in their expression of FER symptoms (Table 1, Supplementary Table S2) and the mean value of severity was $22.47 \%$ with minimum and maximum values of $9.87 \%$ and $49.50 \%$, respectively.

In 2018, no significant differences were reported among the 17 selected hybrids for both locations, with values of severity ranging from 6.50 to $22.17 \%$, but locations and hybrid $\times$ location interactions were significant $(P \leq 0.001$ and $P \leq 0.05$, respectively) (Table 2 , Supplementary Tables S2 and S3). This finding could be explained considering that a lower number of hybrids was evaluated (17 out of 46) and only the best performing materials were chosen. Furthermore, in 2017 fields were sown almost at the same time reducing the effect of climatic differences (Supplementary Figure S1). Conversely, in 2018 the late sowing dates, especially for the field located in Tribiano, determined a shift of the plant flowering time and consequently of the artificial inoculations, influencing the development of the fungus. Additionally, in 2018 more intense rainfalls were recorded from July to October during the maturity stage of maize (about 225 vs $155 \mathrm{~mm}$ in 2017) determining about 10\% less of FER and AER infection (Table 2, Supplementary Figure S1).

Focusing on the different maize hybrid subgroups, the lowest FER percentage was observed for hybrids developed from the CO441 male parent during both growing seasons (18.4 and 12\% for 2017 and 2018, respectively; Figure 1A). Indeed, six out of ten hybrids showing the highest resistance to FER at both locations and years derived from the same male parent (PC8, PC11, PC14, PC1, PC9 and PC10; Table 3).

Significant differences were revealed among hybrids, locations and hybrid $\times$ location for AER in $2017(P \leq 0.05)$, but not in 2018 (Tables 1 and 2, Supplementary Tables S2 and S3). The mean severity was $23.03 \%$ and $12.05 \%$ in 2017 and 2018, respectively. In 2018, AER at T location was not considered due to the sporadic presence of the disease symptoms and the resulting arduous assessing of phenotypes. This was a consequence of the delayed planting date and artificial infections performed at mid-end August, as already discussed for FER. During that period temperatures were not adequate for $A$. flavus development, which usually requires high temperature $\left(37^{\circ} \mathrm{C}\right)$ for optimal growth (O’Brian et al., 2007).

According to the different hybrid subgroups, in 2017 hybrids developed from $\mathrm{S}_{5}$ female lines and CO441 male parent showed weaker AER symptoms (Figure 1B), and among the most resistant hybrids seven were in common with trait resistance to FER (PC8, PC15, PC9, PC11, PC14, PC34 and PC17; Table 3). In contrast, less pronounced differences among female and male parents were observed in 2018.

CO441 is an inbred line with good resistance levels to FER (Lanubile et al., 2010, 2013, 2014b; Maschietto et al., 2017; Reid et al., 2009). The desirable performances of this line were confirmed by our findings not only towards FER, but emerged also to AER, making CO441 as the most promising line to transfer resistance. A previous study on the resistance of hybrids and their parental lines described that the correlation between the performance of the hybrid was higher with the father line than with the mother line (Mesterhazy et al., 2012). This finding is in line with our results confirming the prevalence of the male line in the resistance to ear rots.

CO430 and CO433 were reported as sources of resistance to FER as well (Maschietto et al., 2016; Reid et al., 2009). During hybrid evaluation it was observed that $\mathrm{F}_{1} \mathrm{~s}$ from CO433 exhibited the unfavourable trait of protruding ears or exposed ear tips. This makes ears and kernels 
Table 1. Mean, minimum and maximum values, and two-way analysis of variance (mean squares, MS), for 46 maize experimental hybrids and commercial FAO hybrids evaluated in San Zenone and Tribiano locations during 2017 growing season. 1,2

\begin{tabular}{|c|c|c|c|c|c|c|c|}
\hline \multirow[b]{2}{*}{ Traits } & \multicolumn{3}{|c|}{ Experimental hybrids } & \multirow{2}{*}{$\begin{array}{l}\text { Control hybrids } \\
\text { Mean }\end{array}$} & \multirow[b]{2}{*}{ Hybrid (MS) } & \multirow[b]{2}{*}{ Location (MS) } & \multirow[b]{2}{*}{ Hybrid $\times$ Location (MS) } \\
\hline & Mean & Minimum & Maximum & & & & \\
\hline FER $(\%)$ & 22.47 & 9.87 & 49.50 & 15.74 & $345.50^{* * *}$ & $274.90^{\text {ns }}$ & $186.10^{\text {ns }}$ \\
\hline $\operatorname{AER}(\%)$ & 23.03 & 13.23 & 45.53 & 30.30 & $2.64^{*}$ & $10.93^{*}$ & $2.69^{*}$ \\
\hline N-FER (\%) & 7.66 & 1.63 & 22.70 & 2.51 & $0.90^{* \star *}$ & $0.08^{\mathrm{ns}}$ & $0.63^{* \star *}$ \\
\hline N-AER (\%) & 0.28 & 0.00 & 2.50 & 0.27 & $0.002^{*}$ & $0.0001403^{\text {ns }}$ & $0.0017520^{\text {ns }}$ \\
\hline Fumonisin content (mg/kg) & 121.00 & 33.02 & 262.90 & 126.83 & $28.34^{\mathrm{ns}}$ & $162.91^{* *}$ & $26.78^{\text {ns }}$ \\
\hline Aflatoxin content $(\mu \mathrm{g} / \mathrm{kg})$ & 181.64 & 40.81 & 324.56 & 132.90 & $131.02^{* * *}$ & $9.00^{\mathrm{ns}}$ & $38.74^{\mathrm{ns}}$ \\
\hline Grain yield (t/ha) & 10.22 & 6.11 & 18.44 & 14.99 & $3.24^{* * *}$ & $90.69^{* * *}$ & $0.37^{* \star *}$ \\
\hline Grain moisture (\%) & 15.59 & 13.98 & 16.08 & 16.59 & $6.680 \mathrm{e}^{-06^{* * *}}$ & $2.088 \mathrm{e}^{-04^{* \star *}}$ & $1.450 \mathrm{e}^{-06 n s}$ \\
\hline Silking (DAS) & 77.7 & 73.5 & 82.83 & 79.40 & $1.992 \mathrm{e}^{+18^{* * *}}$ & $5.948 e^{+16 n s}$ & $1.491 \mathrm{e}^{+17^{* * *}}$ \\
\hline Plant height (cm) & 231.7 & 181.7 & 293.0 & 255.70 & $2.31^{* * *}$ & $13.66^{* * *}$ & $0.14^{*}$ \\
\hline Ear height $(\mathrm{cm})$ & 107.02 & 79.83 & 136.5 & 115.42 & $0.12^{* * *}$ & $2.20^{* * *}$ & $0.0095^{*}$ \\
\hline Stalk lodging (\%) & 0.29 & 0.00 & 2.28 & 0.20 & $0.000312^{\mathrm{ns}}$ & $0.02^{* * \star}$ & $0.000319^{n s}$ \\
\hline Smashed $(\%)$ & 6.55 & 0.29 & 23.15 & 2.55 & $0.28^{* * *}$ & $0.006877^{\mathrm{ns}}$ & $0.18^{*}$ \\
\hline
\end{tabular}

Table 2. Mean, minimum and maximum values, and two-way analysis of variance (mean squares, MS), for 17 maize experimental hybrids and commercial FAO hybrids evaluated in San Zenone and Tribiano locations during 2018 growing season. ${ }^{1,2}$

\begin{tabular}{|c|c|c|c|c|c|c|c|}
\hline \multirow[b]{2}{*}{ Traits } & \multicolumn{3}{|c|}{ Experimental hybrids } & \multirow{2}{*}{$\begin{array}{l}\text { Control hybrids } \\
\text { Mean }\end{array}$} & \multirow[b]{2}{*}{ Hybrid (MS) } & \multirow[b]{2}{*}{ Location (MS) } & \multirow[b]{2}{*}{ Hybrid $\times$ Location (MS) } \\
\hline & Mean & Minimum & Maximum & & & & \\
\hline FER $(\%)$ & 12.88 & 6.50 & 22.17 & 11.25 & $10 g^{\text {ns }}$ & $5674^{* * \star}$ & $142^{*}$ \\
\hline $\operatorname{AER}(\%)$ & 12.05 & 5.50 & 25.00 & 11.20 & $2.67^{\mathrm{ns}, 3}$ & 1 & 1 \\
\hline Grain yield (t/ha) & 8.21 & 6.09 & 10.76 & 10.54 & $1.16^{\star \star *}$ & $51.68^{* * *}$ & $0.46^{\mathrm{ns}}$ \\
\hline Grain moisture (\%) & 17.68 & 16.20 & 21.15 & 19.76 & $0.0000033^{* * *}$ & $0.0013822^{* * *}$ & $0.0000015^{*}$ \\
\hline Silking (DAS) & 60.68 & 58.83 & 62.50 & 61.75 & $2.542 \mathrm{e}^{+16^{* \star}}$ & $1.137 \mathrm{e}^{+19^{* * *}}$ & $2.140 \mathrm{e}^{+16^{*}}$ \\
\hline Plant height (cm) & 238.80 & 199.20 & 262.50 & 240.83 & $0.81^{* \star *}$ & $3.57^{* * \star}$ & $0.17^{\star \star \star}$ \\
\hline Ear height $(\mathrm{cm})$ & 128.30 & 109.20 & 140.8 & 129.20 & $0.03^{* * *}$ & $1.28^{* * *}$ & $0.0129^{* *}$ \\
\hline Stalk lodging (\%) & 0.00 & 0.00 & 0.00 & 0 & $3.992 e^{-05 n s}$ & $2.241 \mathrm{e}^{-04^{*}}$ & $4.384 e^{-05 n s}$ \\
\hline Smashed (\%) & 2.09 & 0.00 & 5.49 & 0.60 & $0.09^{n s}$ & $7.15^{* * *}$ & $0.08^{\text {ns }}$ \\
\hline
\end{tabular}

more exposed to birds, insect and wind dispersed spores (Santiago et al., 2015) and for this reason this aspect may have contributed to increased susceptibility.
A significant moderate correlation was obtained between FER and AER severity only at SZ location in 2017 ( $\mathrm{r}=0.58$, $P \leq 0.01$; Figure 2A). Furthermore, a significant weak relationship was observed between the two experimental fields for FER in the same year $(r=0.30, P \leq 0.05$; Figure $2 B)$. 

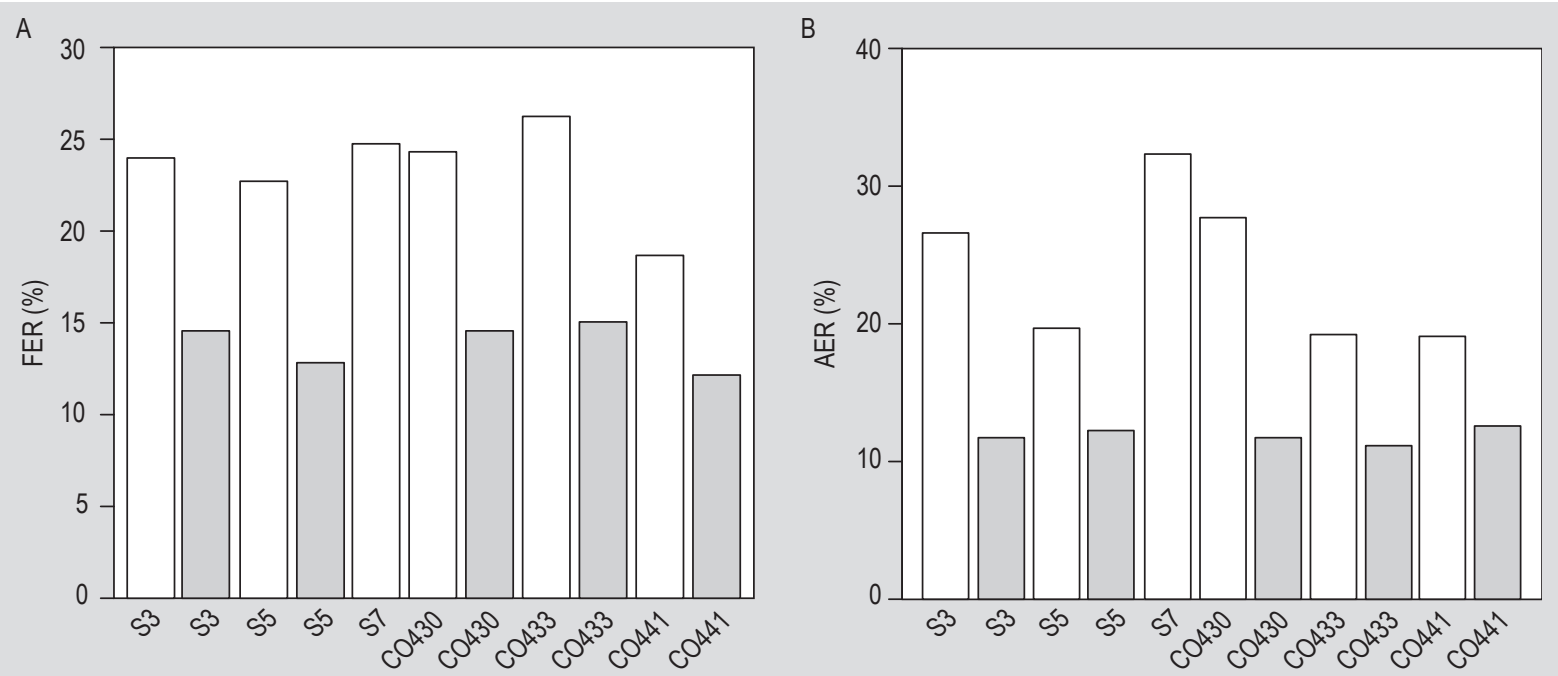

C

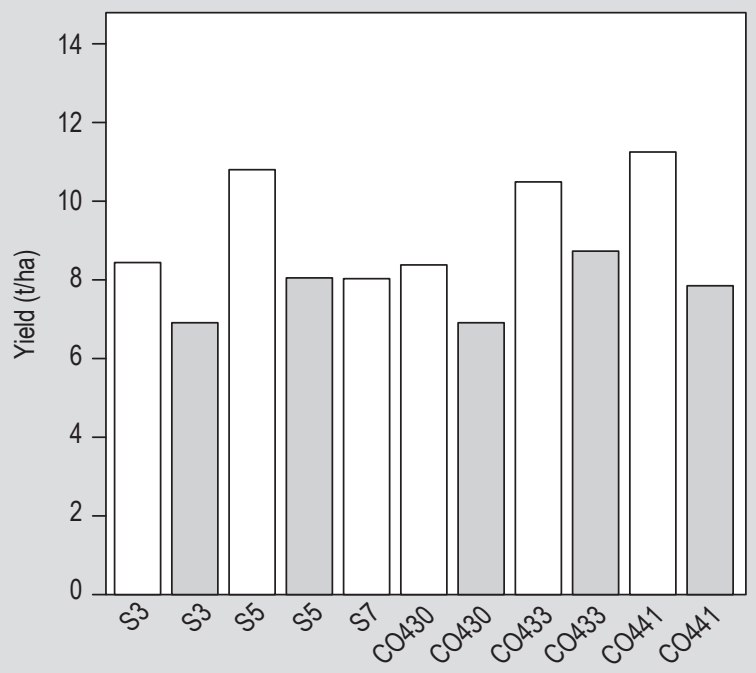

D

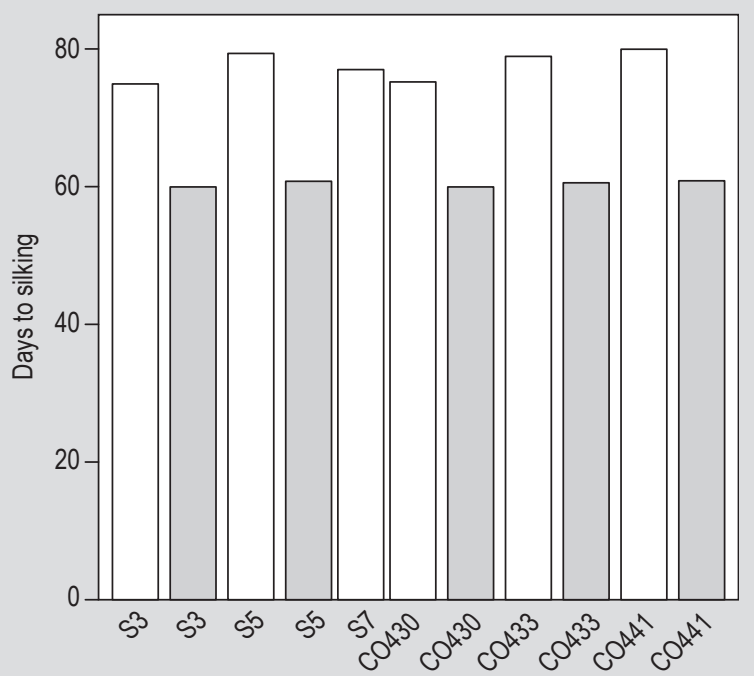

$\mathrm{E}$

$\mathrm{F}$
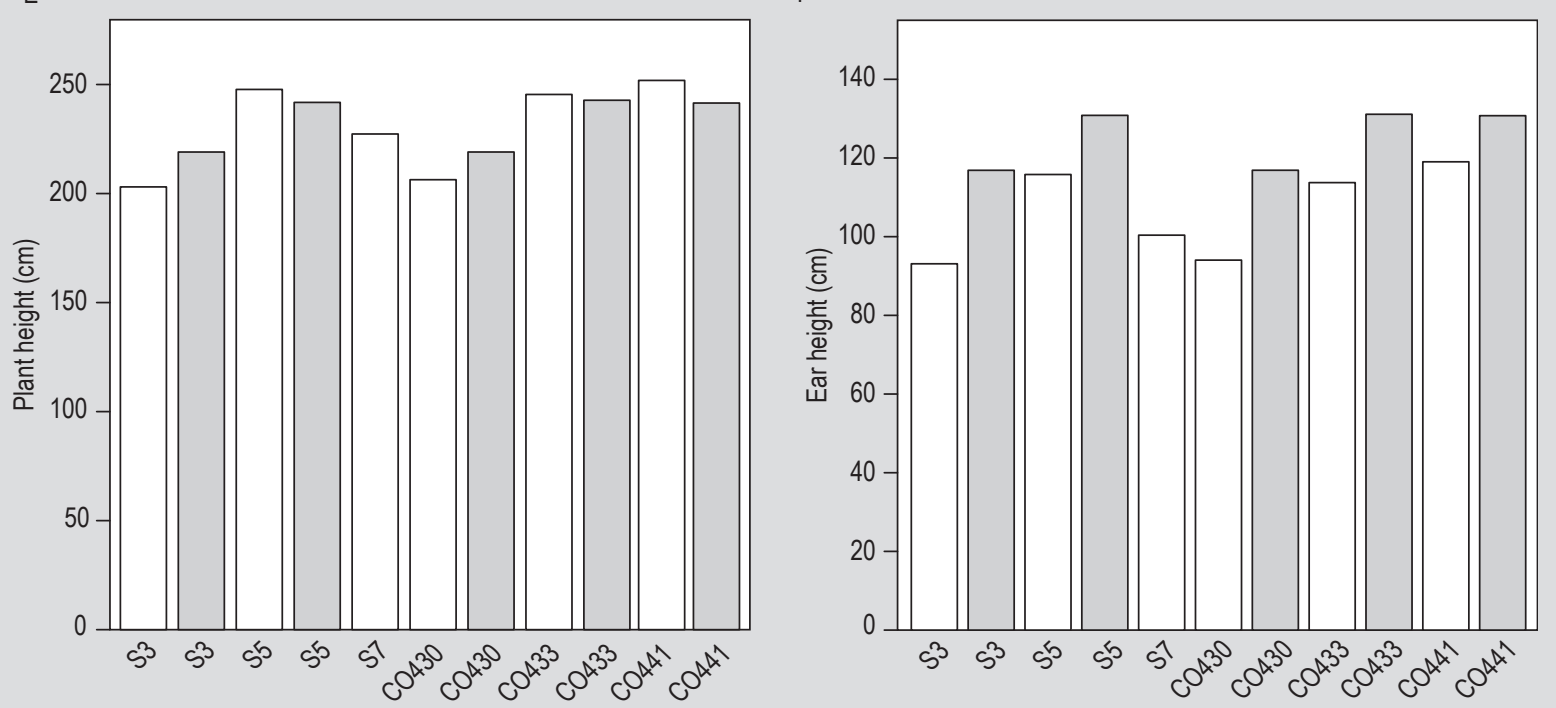

$\square 2017 \quad \square 2018$

Figure 1. Mean values of Fusarium ear rot (FER, \%) and Aspergillus ear rot (AER, \%), yield (t/ha), days to silking, plant height $(\mathrm{cm})$, and ear height $(\mathrm{cm})$ over two locations according to maize hybrid subgroups during 2017 and 2018 growing seasons (white and grey histograms, respectively). The confidence intervals of the means for both years are: panel A 4.3, panel B 4.5, panel C 1.4, panel D 1.5, panel E 14.7, and panel F 8.6. 
Table 3. Mean values for a subset of 10 maize experimental hybrids showing the lowest percentage (\%) of Fusarium ear rot (FER) and Aspergillus ear rot (AER) in San Zenone (SZ) and Tribiano (T) locations during 2017 and 2018 growing seasons. ${ }^{1}$

\begin{tabular}{|c|c|c|c|c|c|c|}
\hline Trait & Hybrid & SZ_17 & T_17 & SZ_18 & T_18 & $\begin{array}{l}\text { Overal } \\
\text { mean }\end{array}$ \\
\hline \multirow[t]{10}{*}{ FER (\%) } & PC32 & $22.77^{b c}$ & $8.87^{b c}$ & $7.00^{\mathrm{a}}$ & $6.00^{b}$ & 11.16 \\
\hline & PC8 & $7.92^{\mathrm{bc}}$ & $17.95^{b c}$ & $6.00^{\mathrm{a}}$ & $13.00^{b}$ & 11.22 \\
\hline & PC11 & $14.20^{c}$ & $5.53^{c}$ & $7.00^{\mathrm{a}}$ & $22.67^{b}$ & 12.35 \\
\hline & PC17 & $12.15^{b c}$ & $10.80^{\mathrm{bc}}$ & $4.67^{\mathrm{a}}$ & $26.33^{b}$ & 13.49 \\
\hline & PC14 & $11.20^{\mathrm{bc}}$ & $17.93^{b c}$ & $8.33^{a}$ & $16.67^{b}$ & 13.53 \\
\hline & PC1 & $13.20^{\mathrm{bc}}$ & $20.67^{b c}$ & $7.00^{\mathrm{a}}$ & $14.33^{b}$ & 13.80 \\
\hline & PC15 & $15.50^{\mathrm{abc}}$ & $21.07^{a b c}$ & $4.67^{a}$ & $15.33^{b}$ & 14.14 \\
\hline & PC9 & $10.87^{a b c}$ & $26.40^{\mathrm{abc}}$ & $6.33^{a}$ & $13.33^{b}$ & 14.23 \\
\hline & PC10 & $14.40^{\mathrm{bc}}$ & $17.67^{b c}$ & $5.00^{a}$ & $20.00^{b}$ & 14.27 \\
\hline & PC34 & $19.07^{a b c}$ & $16.50^{\mathrm{abc}}$ & $7.67^{\mathrm{a}}$ & $15.33^{b}$ & 14.64 \\
\hline \multirow[t]{10}{*}{ AER (\%) } & PC16 & $8.60^{\mathrm{ab}}$ & $17.87^{\mathrm{a}}$ & 10.00 & NA & 12.16 \\
\hline & PC13 & $9.20^{\mathrm{ab}}$ & $23.89^{a}$ & 7.50 & NA & 13.53 \\
\hline & PC8 & $8.67^{a b}$ & $20.33^{a}$ & 12.00 & NA & 13.67 \\
\hline & PC15 & $19.50^{\mathrm{ab}}$ & $12.62^{a}$ & 9.33 & NA & 13.82 \\
\hline & PC9 & $10.33^{a b}$ & $24.70^{\mathrm{a}}$ & 8.33 & NA & 14.46 \\
\hline & PC11 & $20.07^{a b}$ & $13.87^{a}$ & 10.00 & NA & 14.64 \\
\hline & $\mathrm{PC} 12$ & $16.20^{\mathrm{ab}}$ & $19.07^{a}$ & 9.00 & NA & 14.76 \\
\hline & PC14 & $21.50^{\mathrm{ab}}$ & $19.25^{a}$ & 7.00 & NA & 15.92 \\
\hline & PC34 & $29.33^{a b}$ & $13.40^{\mathrm{a}}$ & 8.67 & NA & 17.13 \\
\hline & PC17 & $19.70^{\mathrm{ab}}$ & $19.67^{a}$ & 14.00 & NA & 17.79 \\
\hline
\end{tabular}

${ }^{1}$ Means followed by the same letter in the column do not differ significantly at the 0.05 probability level based on Bonferroni test.

The absence of correlation between the two diseases and the two locations in 2018 has to be most likely imputed to the late and different sowing times that resulted in postponed fungal infections, thus penalising their growth.

Identification of the traits that contribute to resistance to both FER and AER is an important task in breeding programs. Genotypes showing resistance to both A. flavus and $F$. verticillioides are known (Henry et al., 2009) and the correlation between resistances against the two fungi was previously reported (Guo et al., 2017; Robertson-Hoyt et al., 2007; Rose et al., 2017). Quantitative trait loci (QTL) associated to different ear rot pathogens suggest that these traits may be genetically linked (Gaikpa and Miedaner, 2019). In a previous study analysing the defence responses towards different FER-causing Fusarium spp. and A. flavus, an overlap of genes and enzymatic pathways was observed following the infection with these pathogens (Lanubile et al., 2015), supporting the feasibility of selecting materials against multiple fungi at the same time.

\section{Ear rots under natural infection}

In 2017, susceptibility to natural infection caused by $F$. verticillioides and $A$. flavus was measured and $\mathrm{F}_{1}$ hybrids significantly differed in Tribiano and San Zenone for both N-FER $(P \leq 0.001)$ and N-AER $(P \leq 0.05)$ (Table 1 ; Supplementary Table 22 ). Hybrid $\times$ location interaction was significant $(P \leq 0.001)$ for N-FER too (Table 1; Supplementary Table S2). The range of N-FER was from 1.63 to $22.70 \%$ with a mean of $7.66 \%$. Natural AER was detected only in 16 hybrids with a maximum value of $2.67 \%$ and an average of $0.28 \%$. Interestingly, strong and moderate correlations were observed in T $(\mathrm{r}=0.73, P \leq 0.01)$ and $\mathrm{SZ}(\mathrm{r}=0.55, P \leq 0.01)$ between artificial and natural susceptibility of hybrids to FER. A weaker $(\mathrm{r}=0.28)$, but significant $(P \leq 0.05)$ correlation was determined between the two locations for N-FER. No significant correlations were found for N-AER between $\mathrm{T}$ and SZ experimental fields. Natural infection of FER and AER was not measured in 2018 due to the almost complete absence of both fungi.

Up to sixteen species of Fusarium can coexist in field (Dorn et al., 2011), and for the same species multiple strains can be present and not adequately controllable (Mesterhazy et al., 2012). Additionally, natural infections are not always adequate and uniform, and for these reasons they should not be considered for selection program. Interestingly, significant correspondence between the results of resistance to FER after natural and artificial inoculations were observed in this study. Despite genotype differences are much wider under artificial inoculation, many breeders use natural infection pressure for the selection of disease resistant genotypes (Balconi et al., 2014; Mesterhazy et al., 2012). Out results evidenced the validity of the two tests both advisable for resistance breeding purposes.

\section{Mycotoxin contamination}

In 2017, artificially inoculated $\mathrm{F}_{1}$ maize hybrids were evaluated for total fumonisin $\left(B_{1}+B_{2}+B_{3}\right)$ and aflatoxin $\left(B_{1}+B_{2}+G_{1}+G_{2}\right)$ content (Table 1, Supplementary Table S2). All samples were contaminated with both mycotoxins, exceeding the European legislation-recommended level in unprocessed maize of $4 \mathrm{mg} / \mathrm{kg}$ for fumonisins and 0.005 $\mu \mathrm{g} / \mathrm{kg}$ for aflatoxins. Fumonisin levels varied among hybrids with total fumonisin concentrations averaging $121 \mathrm{mg} / \mathrm{kg}$ (ranging from 33.02 to $262.90 \mathrm{mg} / \mathrm{kg}$ ) and total aflatoxins averaging $181.64 \mu \mathrm{g} / \mathrm{kg}$ (ranging from 40.81 to 324.56 $\mu \mathrm{g} / \mathrm{kg}$ ). Overall, differences in fumonisin contamination were not significant among hybrids, but they were for locations $(P \leq 0.001$; Table 1$)$. Conversely, hybrids varied significantly for the aflatoxin content $(P \leq 0.001$; Table 1$)$.

The less contaminated hybrids were PC17, PC44 and PC34 for fumonisins, whereas PC9, PC8 and PC20 were less contaminated with aflatoxins (Table 4). Interestingly, PC8, 


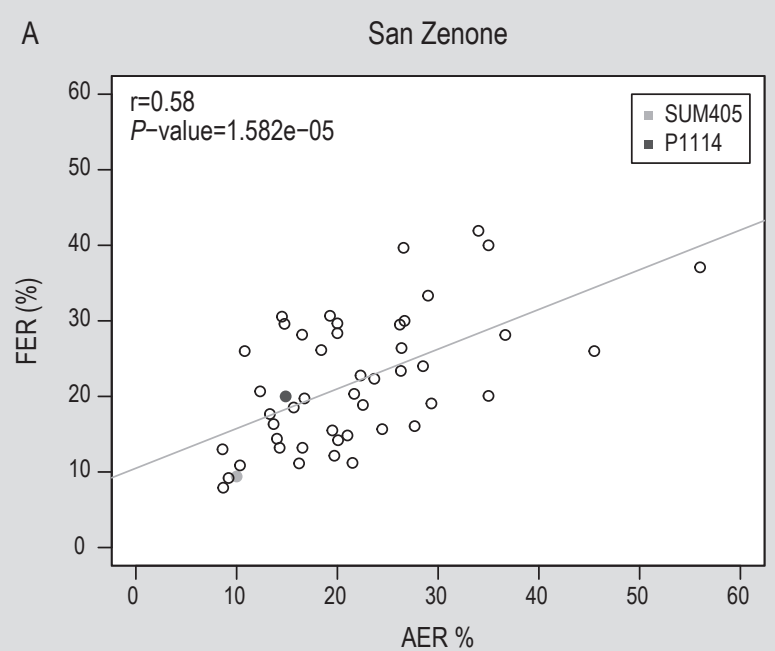

C

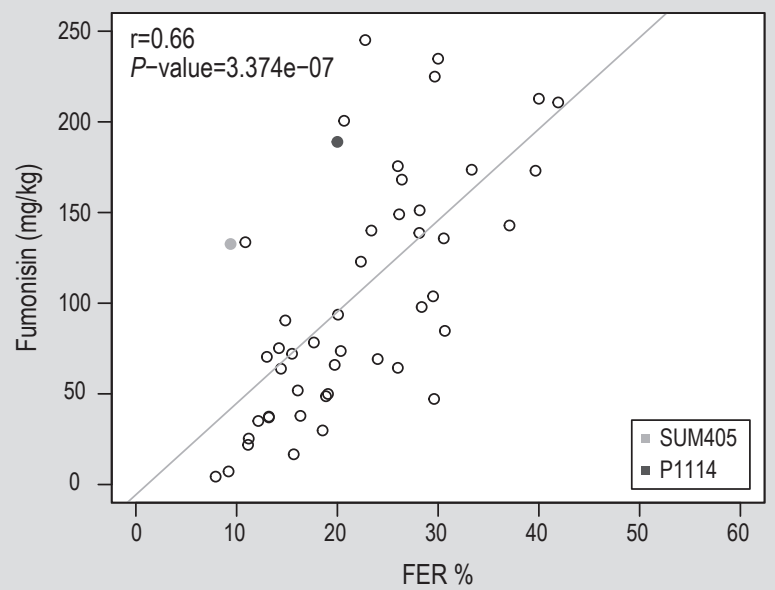

E

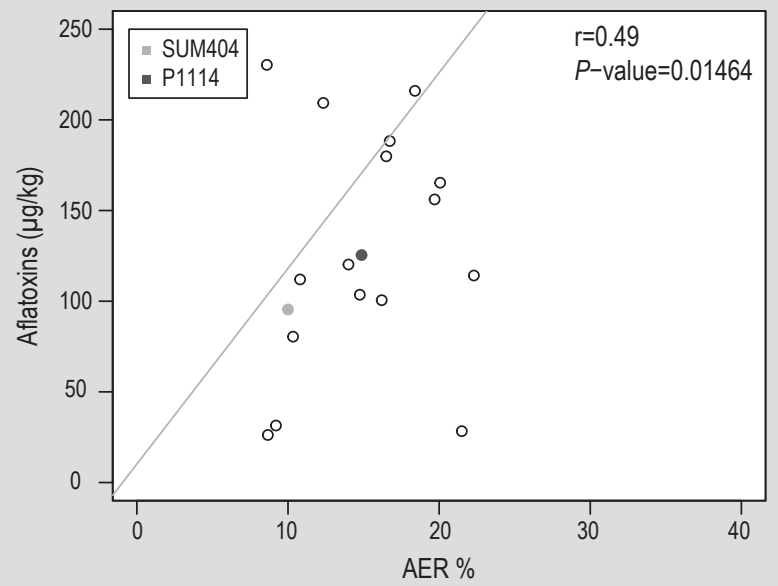

B

FER

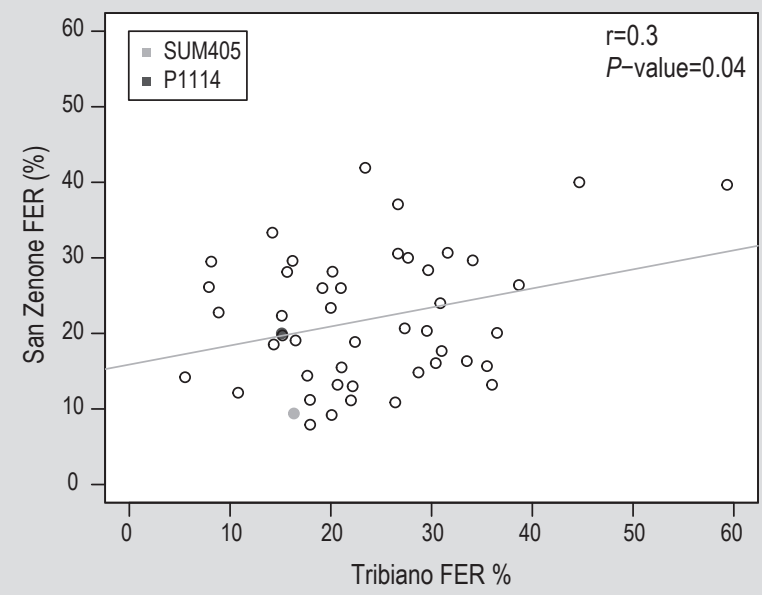

D

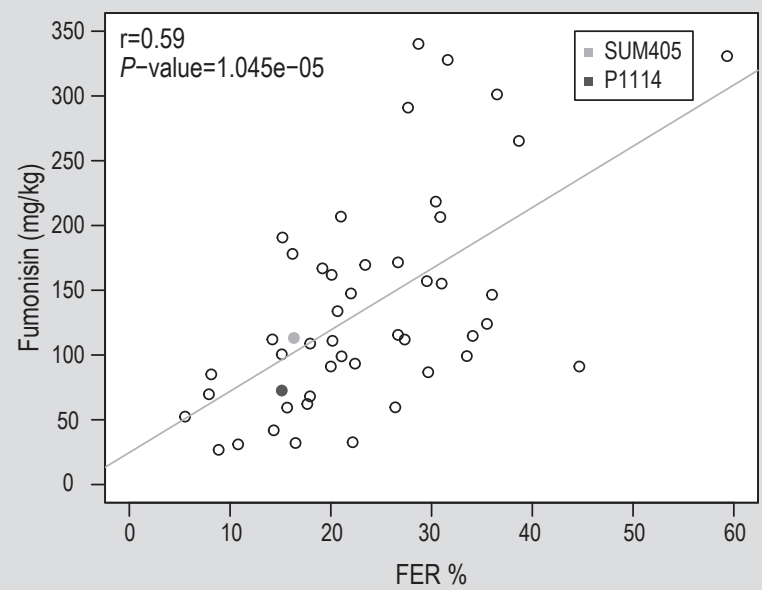

$\mathrm{F}$

Yield

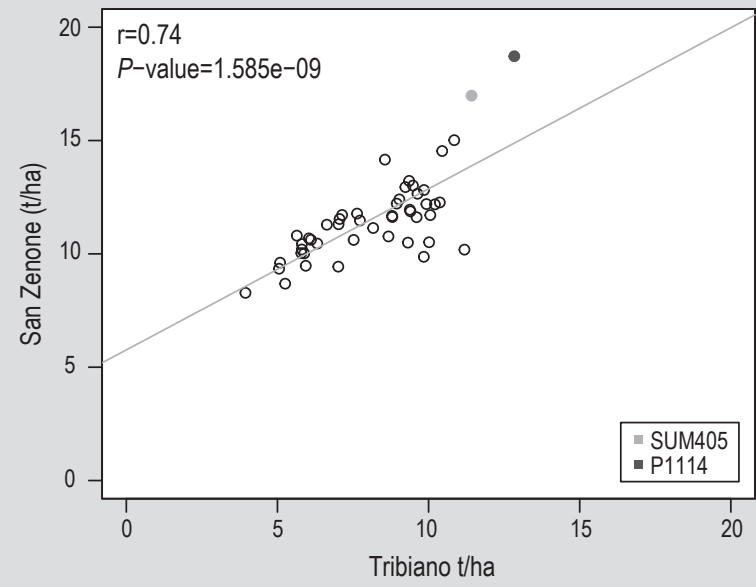

Figure 2. Correlations between traits during the 2017 growing season. (A) Percentage of Fusarium ear rot (FER) and Aspergillus ear rot (AER) at San Zenone location; (B) percentage of FER between San Zenone and Tribiano locations; percentage of FER and fumonisins ( $\mathrm{mg} / \mathrm{kg}$ ) at San Zenone and Tribiano locations (C and D, respectively); $(E)$ percentage of AER and aflatoxins ( $\mu \mathrm{gg} / \mathrm{kg})$ at San Zenone location; (F) grain yield (t/ha) between San Zenone and Tribiano locations; (G) percentage of FER and grain yield (t/ha) at San Zenone location; $(H)$ percentage of AER and grain yield (t/ha) at San Zenone location; grain yield (t/ha) and days to silking (DAS) at San Zenone and Tribiano locations (I and L, respectively); (M) percentage of FER and DAS at San Zenone location; and (N) percentage of AER and DAS at San Zenone location. 
G

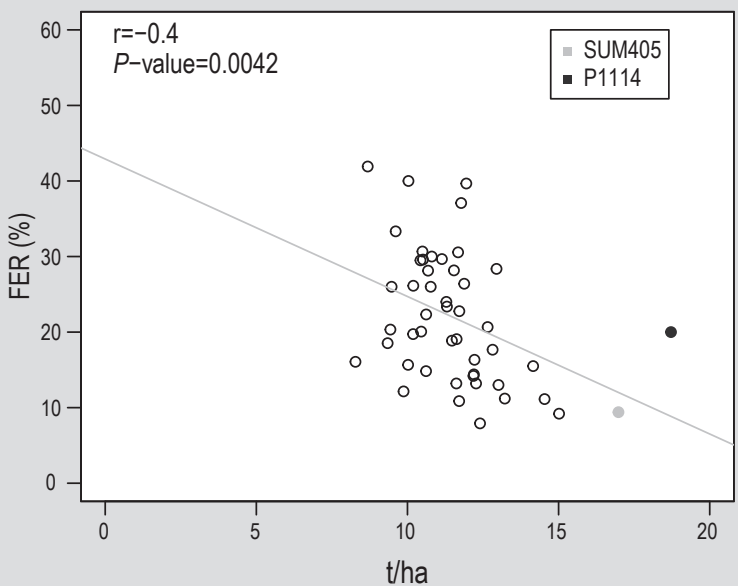

I

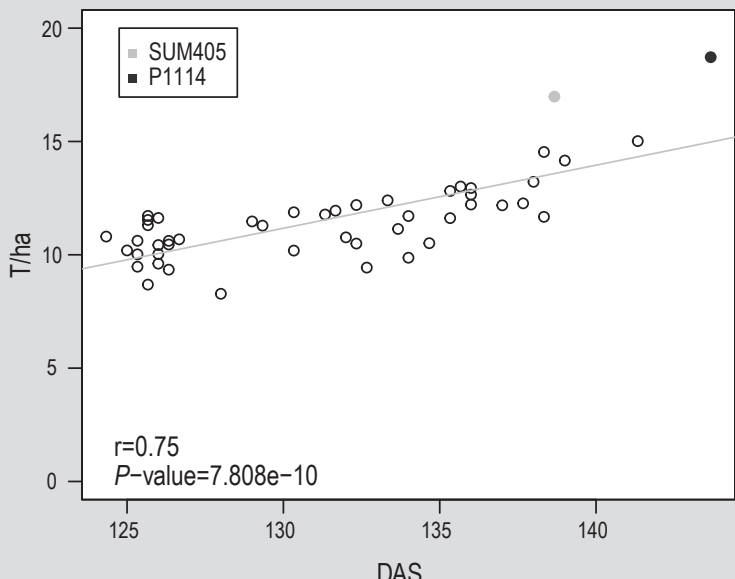

K

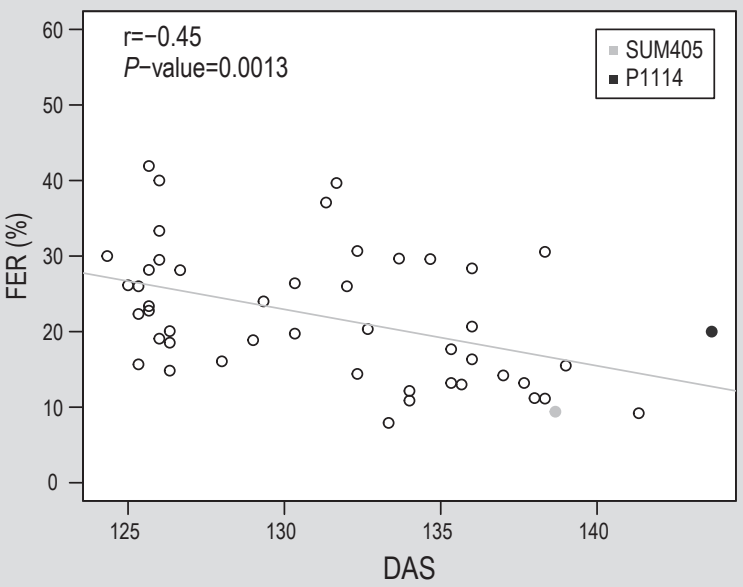

$\mathrm{H}$

San Zenone

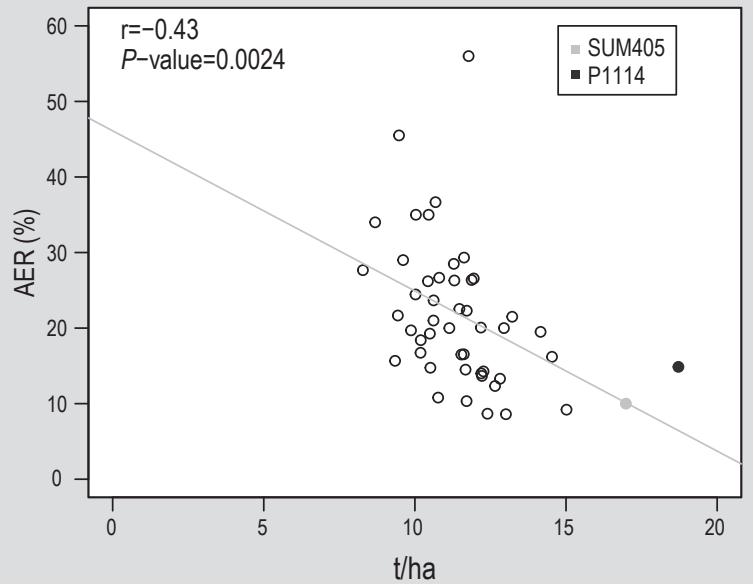

J

Tribiano

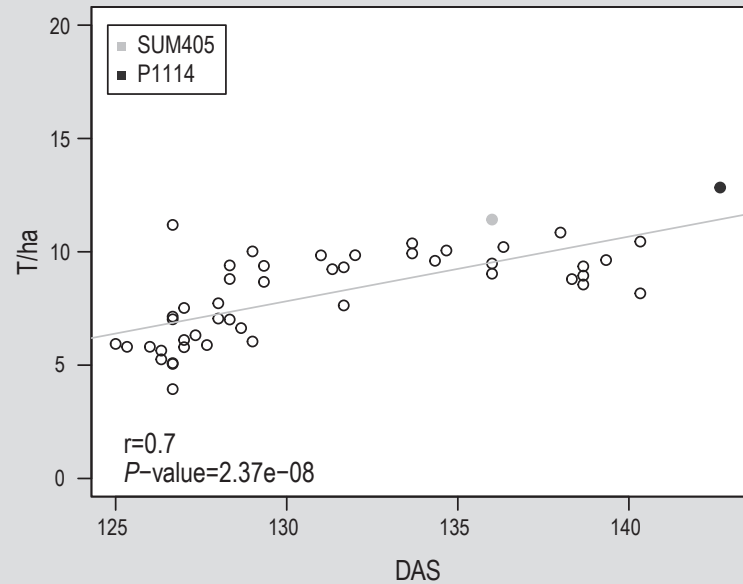

L

San Zenone

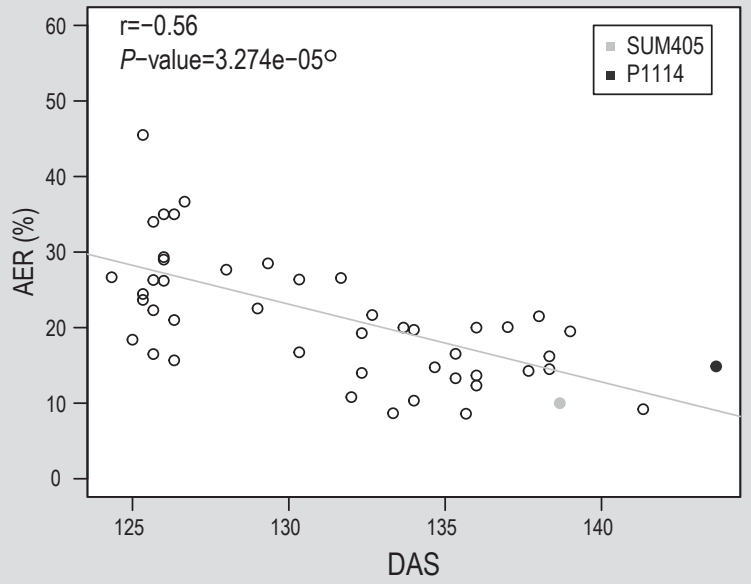

Figure 2. Continued. 
PC10, PC11 and PC14 were among the most resistant hybrids to both mycotoxins and PC8, PC11 and PC14 showed also elevated resistance to FER and AER (Tables 3 and 4). Once again, the best performers were hybrids derived from the male parent CO441 and female lines $\mathrm{S}_{5}$ coherently with previous findings regarding FER and AER. These three hybrids may be favourable sources of resistance in breeding efforts to reduce the presence of both diseases and their associated mycotoxins.

Good correlations between resistance to FER and accumulation of fumonisins was observed for both SZ $(\mathrm{r}=0.66, P \leq 0.01$; Figure $2 \mathrm{C})$ and $\mathrm{T}(\mathrm{r}=0.57, P \leq 0.01$; Figure 2D). Moreover, a moderate correlation of 0.49 was observed between AER severity and aflatoxin content in the location of $\mathrm{SZ}(P \leq 0.01$; Figure $2 \mathrm{E}$ ), suggesting that climatic conditions at Tribiano seemed more unfavourable for $A$. flavus growth and aflatoxin production, probably due to the more severe rainfalls and lower temperatures recorded in this location (Supplementary Figure S1).

Although these experiments indicated a positive overall relationship between ear rots and subsequent mycotoxin contamination (Figure 2), some hybrids did not follow this

Table 4. Mean values for a subset of 10 maize hybrids showing the lowest content of fumonisins $\left(B_{1}+B_{2}+B_{3}\right)$ and aflatoxins $\left(B_{1}+B_{2}+G_{1}+G_{2}\right)$ expressed in $\mathrm{mg} / \mathrm{kg}$ and $\mu \mathrm{g} / \mathrm{kg}$, respectively, in San Zenone (SZ) and Tribiano (T) during 2017 growing season. ${ }^{1}$

\begin{tabular}{|c|c|c|c|c|}
\hline Trait & Hybrid & SZ_17 & T_17 & Overall mean \\
\hline \multirow[t]{10}{*}{ Fumonisin (mg/kg) } & PC17 & $35.03^{a}$ & $31.01^{a b}$ & 33.02 \\
\hline & PC44 & $29.82^{a}$ & $41.85^{a b}$ & 35.84 \\
\hline & PC34 & $49.94^{a}$ & $32.06^{a b}$ & 41.00 \\
\hline & PC14 & $25.33^{a}$ & $68.09^{a b}$ & 46.71 \\
\hline & PC16 & $70.41^{a}$ & $32.65^{a b}$ & 51.53 \\
\hline & PC8 & $4.35^{\mathrm{a}}$ & $108.83^{a b}$ & 56.59 \\
\hline & PC10 & $63.86^{a}$ & $62.17^{a b}$ & 63.02 \\
\hline & PC11 & $75.21^{a}$ & $52.44^{a b}$ & 63.82 \\
\hline & PC5 & $37.86^{a}$ & $99.16^{\mathrm{ab}}$ & 68.51 \\
\hline & PC26 & $16.66^{\mathrm{a}}$ & $124.02^{\mathrm{ab}}$ & 70.34 \\
\hline \multirow[t]{10}{*}{ Aflatoxins $(\mu \mathrm{g} / \mathrm{kg})$} & PC9 & $80.44^{b}$ & $1.17^{b}$ & 40.81 \\
\hline & PC8 & $26.22^{a b}$ & $57.50^{a b}$ & 41.86 \\
\hline & PC20 & $112.00^{a b}$ & $44.67^{a b}$ & 78.33 \\
\hline & PC14 & $28.33^{a b}$ & $134.33^{a b}$ & 81.33 \\
\hline & PC32 & $114.17^{a b}$ & $91.45^{\mathrm{ab}}$ & 102.81 \\
\hline & PC13 & $31.44^{\mathrm{ab}}$ & $180.67^{a b}$ & 106.06 \\
\hline & PC10 & $120.22^{a b}$ & $100.00^{a b}$ & 110.11 \\
\hline & PC11 & $165.33^{a b}$ & $56.33^{a b}$ & 110.83 \\
\hline & PC12 & $100.56^{a b}$ & $156.56^{\mathrm{ab}}$ & 128.56 \\
\hline & PC25 & $103.56^{a b}$ & $168.78^{a b}$ & 136.17 \\
\hline
\end{tabular}

trend and results should be considered with caution because disease development and toxin accumulation were not uniform at all locations and years. Previous studies reported that differences on fumonisin accumulation existed for materials with the same disease severity (Mesterhazy et al., 2012) and correlations between mycotoxins and fungal growth were variable (Munkvold et al., 2003). Conversely, several works found good correlations (more than 0.85) between these two traits (Hung and Holland, 2012; Robertson et al., 2006). Recently, Maschietto et al. (2017) reported a relatively high phenotypic correlation between FER and the presence of fumonisins. Moreover, they identified eight common QTL for these two traits further reinforcing the hypothesis of common resistance maize genetic mechanisms. Similar contrasting data were described for resistance to AER and aflatoxins. These two traits were reported to be highly correlated by Robertson-Hoyt et al. (2007). In another study, a strong genetic correlation between the AER and the aflatoxin concentration was recorded only in one location out of the four evaluated (Okoth et al., 2017). Furthermore, Rose et al. (2017) identified two lines previously described as resistant to aflatoxin accumulation showing resistance to FER and fumonisin production.

Mycotoxin analysis was not carried out on samples harvested and evaluated in 2018 growing season due to the more fluctuating climatic conditions that caused a lower incidence of both ear rots. Additional in-depth analysis is required to elucidate the potential mechanism behind this phenomenon.

\section{Agronomic performances of hybrids}

The agronomic performances of the $46 \mathrm{~F}_{1}$ hybrids are shown in Tables 1 and 2. Significant differences among hybrids were observed for all the agronomic traits considered in 2017 and 2018 for both locations $(P \leq 0.001)$, with the exception of stalk lodging in both growing seasons and the percentage of smashed plants in 2018 (Tables 1 and 2, Supplementary Tables S2 and S3). Locations were significantly different for all traits in both years $(P \leq 0.001)$, except DAS and percentage of smashed plants in 2017 (Tables 1 and 2, Supplementary Tables S2 and S3). Furthermore, hybrids $\times$ location interaction was significant for almost all characters considered, excluding the percentage of stalk lodging in both years, grain moisture in 2017, and grain yield and percentage of smashed plants in 2018 (Tables 1 and 2, Supplementary Tables S2 and S3).

During hybrid development, grain yield represents a driving factor of breeding purposes. Average productions of $11.92 \mathrm{t} / \mathrm{ha}$ and $8.53 \mathrm{t} / \mathrm{ha}$ in 2017 , and $10.05 \mathrm{t} / \mathrm{ha}$ and $6.38 \mathrm{t} /$ ha in 2018 were obtained in SZ and T, respectively (Tables 1 and 2, Supplementary Table S2). Despite the highly significant good correlation observed for this trait 
between the two locations in 2017 ( $\mathrm{r}=0.74, P \leq 0.01$; Figure 2F), undeniably, San Zenone and the year 2017 represented the most favourable environment and growing season for the evaluation of the $F_{1}$ hybrids and the expression of their yield performances. Indeed, moderate negative correlations were described only for SZ between susceptibility to both ear rots and grain yield in $2017(\mathrm{r}=-0.40, P \leq 0.01$ and $\mathrm{r}=-$ $0.43, P \leq 0.01$ for FER and AER, respectively; Figure $2 \mathrm{G}$ and $2 \mathrm{H}$ ), suggesting that the best performing hybrids exhibited the lower levels of FER and AER diseases. According to different hybrid groups, yield potentials were higher for hybrids deriving from $\mathrm{CO} 441$ and $\mathrm{CO} 433$ male parents and $\mathrm{S}_{5}$ female lines (Figure 1C), which had longer DAS compared to $\mathrm{S}_{3}$ and $\mathrm{S}_{5}$ lines (Supplementary Table S2). As expected, a strong positive correlation was observed between DAS and grain yield for both San Zenone $(\mathrm{r}=0.75$, $P \leq 0.01)$ and Tribiano $(\mathrm{r}=0.69, P \leq 0.01)$ (Figure $2 \mathrm{I}$ and $2 \mathrm{~L}$ ).

DAS ranged from 73 to 83 days during 2017 and from 59 to 62 days during 2018 (Tables 1 and 2, Supplementary Table S2). Wider differences in DAS among hybrids were observed in 2017 (11 days) than 2018 (3 days), as a consequence of late planting for experimental fields. Delayed planting shortened the effective growing season, influencing flowering and fungal development as well (Nielsen et al., 2002). Not particular differences were observed among the different hybrid groups for DAS, but in general it resulted higher in 2017, as previously described (Figure 1D). Moderately negative correlations were detected between DAS and FER $(\mathrm{r}=-0.45, P \leq 0.01)$ and DAS and AER $(\mathrm{r}=-0.56, P \leq 0.01)$ at SZ location in 2017 (Figure $2 \mathrm{M}$ and $2 \mathrm{~N}$ ), whereas no correlations were observed in Tribiano. It was previously described that late maturing inbreds and hybrids were potentially more at risk of severe ear rots (Battilani et al., 2008; Eller et al., 2008; Lanubile et al., 2011; Santiago et al., 2015). Instead, an opposite trend derived from our findings. Similarly, negative correlations were detected between silking dates and severity to $F$. verticilliodes and Fusarium graminearum ear rots with later genotypes being more resistant (Mesterhazy et al., 2012).

At harvesting, the percentage of grain moisture was not uniform among hybrids, ranging from 13.98 to $16.08 \%$ in 2017 and 16.20 and $21.15 \%$ in 2018 (Tables 1 and 2, Supplementary Tables S2 and S3). Grain is normally harvested at a moisture content of $20 \%$, followed by artificial drying of the grain stock to avoid the presence of ear rots caused by $F$. verticilliodes, F. graminearum and A. flavus and the resulting presence of mycotoxins. The rate of dry down of hybrids is a consequence of the genetic background of the material and is relevant for fungal infections and micotoxin accumulation. A previous study concerning dynamic of water activity and humidity of maize kernels revealed how 'slow dry down' hybrids were more prone to fumonisin accumulation, irrespective of their maturity class (Battilani et al., 2011).
The mean of plant and ear height varied significantly in $\mathrm{F}_{1}$ hybrids at both locations and years $(P \leq 0.001)$ (Tables 1 and 2 , Supplementary Tables S2 and S3). The average of both traits was higher in 2018 than in 2017, with mean values of $231.7 \mathrm{~cm}$ and $107.02 \mathrm{~cm}$ in 2017 and $238.8 \mathrm{~cm}$ and $128.3 \mathrm{~cm}$ in 2018 for plant and ear height, respectively. This finding could be due to the selection of hybrids carried out after the first year of trials in 2017, where the $F_{1}$ hybrids with higher values of ear rot severity and visually unsatisfactory were discarded. This was in line with the susceptibility to lodging and the percentage of smashed plants observed in the two years, reported to a greater extent in 2017, whereas the percentage of lodging was not recorded in 2018 at all (Tables 1 and 2, Supplementary Tables S2 and S3). As already come to light for the other traits, ear and plant height were higher for hybrids deriving from $\mathrm{CO} 441$ and $\mathrm{CO} 433$ male parents and $\mathrm{S}_{5}$ female lines for both years, but more markedly for the year 2018 where the best performing 17 hybrids were chosen (Figure 1E and 1F). Previous studies reported that plant height, ear height, grain moisture and also, plant stand ability, had highly significant genetic and phenotypic direct effects on grain yield (Adu et al., 2016; Filipovic et al., 2014). Selection of hybrids having the best yield related traits represents an added value for the most disease and mycotoxin resistant materials identified in this study.

\section{Conclusions}

A major concern for global food and feed security is represented by the contamination of maize with Fusarium spp., Aspergillus spp. and their associated mycotoxins. Breeding for resistance using inbred lines and hybrids with high level of resistance to $F$. verticillioides/fumonisins and A. flavus/aflatoxins is still viewed to be one of the best approaches to mitigate this issue in maize. In this study, we identified seven hybrids (PC8, PC15, PC9, PC11, PC14, PC34 and PC17) resistant to both FER and AER diseases considering the overall locations and growing seasons, and three of these (PC8, PC11 and PC14) were also amongst the least contaminated hybrids in 2017. In the current study the identification of new hybrids and inbred lines with resistance to kernel infection by $F$. verticillioides and $A$. flavus provide additional sources of resistance that could be exploited in other breeding programs. This evidence is substantiated by the results on single crosses using parental lines that have been identified as resistant. Such genotypes can be used to develop early-medium maturity class of maize hybrids for use in areas of the country likely to have ear rot issues.

\section{Supplementary material}

Supplementary material can be found online at https://doi. org/10.3920/WMJ2019.2554. 
Figure S1. Climatic variables represented by minimum, mean and maximum temperatures and rainfall verified at San Zenone and Tribiano locations during 2017 and 2018 years.

Table S1. List of hybrids, their origin, days to silking and to anthesis for female and male lines, respectively.

Table S2. Phenotypic data collected from the $46 \mathrm{~F}_{1}$ hybrids and the four commercial hybrids evaluated during 2017 and 2018 years at San Zenone and Tribiano locations.

Table S3. Least significance difference analysis of the phenotypic traits from the $46 \mathrm{~F}_{1}$ hybrids and the four commercial hybrids evaluated during 2017 and 2018 years at San Zenone and Tribiano locations.

\section{Acknowledgements}

The authors thank Agricola 2000 for field trial assistance and Federico Grignaffini for helping with infection experiments. This research was funded by the European Union's Horizon 2020 research and innovation programme under Grant Agreement No. 678781 (MycoKey).

\section{Conflict of interest}

The authors declare no conflict of interest.

\section{References}

Adu, G.B., Akromah, R., Abdulai, M.S., Obeng-Antwi, K., Alidu, H. and Tengan, K.M.L., 2016. Trait association for improved grain yield of extra-early maturing maize hybrids evaluated in the forest and transitional zones of Ghana. Australian Journal of Crop Science 10: 1127-1135.

Balconi, C., Berardo, N., Locatelli, S., Lanzanova, C., Torri, A. and Redaelli, R., 2014. Evaluation of ear rot (Fusarium verticillioides) resistance and fumonisin accumulation in Italian maize inbred lines. Phytopathologia Mediterranea 53: 14-26.

Battilani, P., Formenti, S., Ramponi, C. and Rossi, V., 2011. Dynamic of water activity in maize hybrids is crucial for fumonisin contamination in kernels. Journal of Cereal Science 54: 467-472.

Battilani, P., Pietri, A., Barbano, C., Scandolara, A., Bertuzzi, T. and Marocco, A., 2008. Logistic regression modeling of cropping systems to predict fumonisin contamination in maize. Journal of Agricultural and Food Chemistry 56: 10433-10438.

Chungu, C., Mather, D.E., Reid, L.M. and Hamilton, R.I., 1996. Comparison of techniques for inoculating maize silk, kernel, and cob tissues with Fusarium graminearum. Plant Disease 80: 81-84.

De Mendiburu, F., 2017. Agricolae: statistical procedures for agricultural research. Available at: https://CRAN.R-project.org/ package $=$ agricolae

Desjardins, A.E. and Proctor, R.H., 2007. Molecular biology of Fusarium mycotoxins. International Journal of Food Microbiology 119: 47-50.
Dorn, B., Forrer, H.R., Jenny, E., Wettstein, F.E., Bucheli, T.D. and Vogelgsang, S., 2011. Fusarium species complex and mycotoxins in grain maize from maize hybrid trials and from grower's fields. Journal of Applied Microbiology 111: 693-706.

Eller, M., Robertson-Hoyt, L.A., Payne, G.A. and Holland, J.B., 2008. Grain yield and Fusarium ear rot of maize hybrids developed from lines with varying levels of resistance. Maydica 53: 231-237.

Filipovic, M., Babic, M., Delic, N., Bekavac, G. and Babic, V., 2014. Determination of relevant breeding criteria by the path and factor analysis in maize. Genetika 46: 49-58.

Food and Agriculture Organization of the United Nations (FAO), 2017. The future of food and agriculture - trends and challenges. FAO, Rome, Italy.

Food and Agriculture Organization of the United Nations (FAO), 2018. FAOSTAT statistics database collections. FAO, Rome, Italy.

Gaikpa, D.S. and Miedaner, T., 2019. Genomics-assisted breeding for ear rot resistances and reduced mycotoxin contamination in maize: methods, advances and prospects. Theoretical and Applied Genetics 132: 2721-2739.

Guo, B., Ji, X., Ni, X., Fountain, J.C., Li, H., Abbas, H.K., Lee, R.D. and Scully, B.T., 2017. Evaluation of maize inbred lines for resistance to pre-harvest aflatoxin and fumonisin contamination in the field. Crop Journal 5: 259-264.

Henry, W.B., Williams, W.P., Windham, G.L. and Hawkins, L.K., 2009. Evaluation of maize inbred lines for resistance to Aspergillus and Fusarium ear rot and mycotoxin accumulation. Agronomy Journal 101: 1219-1226.

Hope, R.M., 2013. Rmisc: Rmisc: Ryan Miscellaneous. R package version 1.5. Available at: https://CRAN.R-project.org/package $=$ Rmisc

Hung, H. and Holland, B.J., 2012. Diallel analysis of resistance to Fusarium ear rot and fumonisin contamination in maize. Crop Science 52: 2173-2181.

Ju, M., Zhou, Z., Mu, C., Zhang, X., Gao. J., Liang, Y., Chen, J., Wu, Y., Li, X., Wang, S., Wen, J., Yang, L. and Wu, J., 2017. Dissecting the genetic architecture of Fusarium verticillioides seed rot resistance in maize by combining QTL mapping and genome-wide association analysis. Scientific Reports 7: 46446.

King, S.B. and Scott, G.E., 1982. Field inoculation techniques to evaluate maize for reaction to kernel infection by Aspergillus flavus. Phytopatology 72: 782-785.

Lanubile, A., Ferrarini, A., Maschietto, V., Delledonne, M., Marocco, A. and Bellin, D., 2014b. Functional genomic analysis of constitutive and inducible defense responses to Fusarium verticillioides infection in maize genotypes with contrasting ear rot resistance. BMC Genomics 15: 710 .

Lanubile, A., Logrieco, A., Battilani, P., Proctor, R.H. and Marocco, A., 2013. Transcriptional changes in developing maize kernels in response to fumonisin-producing and nonproducing strains of Fusarium verticillioides. Plant Science 210: 183-192.

Lanubile, A., Maschietto, V. and Marocco, A., 2014a. Breeding maize for resistance to mycotoxins. In: Leslie, J.F. and Logrieco, A.F. (eds.) Mycotoxin reduction in grain chains. John Wiley \& Sons, Ltd., Chichester, UK, pp. 37-58. 
Lanubile, A., Maschietto, V., Battilani, P. and Marocco, A., 2017b. Infection with toxigenic and atoxigenic strains of Aspergillus flavus induces different transcriptional signatures in maize kernels. Journal of Plant Interactions 12: 21-30.

Lanubile, A., Maschietto, V., Borrelli, V.M., Stagnati, L., Logrieco, A.F. and Marocco, A., 2017a. Molecular basis of resistance to Fusarium ear rot in maize. Frontiers in Plant Science 8: 1774.

Lanubile, A., Maschietto, V., De Leonardis, S., Battilani, P., Paciolla, C. and Marocco, A., 2015. Defense responses to mycotoxin producing fungi Fusarium proliferatum, F. subglutinans, and Aspergillus flavus in kernels of susceptible and resistant maize genotypes. Molecular Plant-Microbe Interaction 28: 546-557.

Lanubile, A., Pasini, L. and Marocco, A., 2010. Differential gene expression in kernels and silks of maize lines with contrasting levels of ear rot resistance after Fusarium verticillioides infection. Journal of Plant Physiololgy 167: 1398-406.

Lanubile, A., Pasini, L., Lo Pinto, M., Battilani, P., Prandini, A. and Marocco, A., 2011. Evaluation of broad spectrum sources of resistance to Fusarium verticillioides and advanced maize breeding lines. World Mycotoxin Journal 1: 43-51.

Marin, S., Ramos, A.J., Cano-Sancho, G. and Sanchis V., 2013. Mycotoxins: occurrence, toxicology, and exposure assessment. Food and Chemical Toxicology 60: 218-237.

Maschietto, V., Colombi, C., Pirona, R., Pea, G., Strozzi, F., Marocco, A., Rossini, L. and Lanubile, A., 2017. QTL mapping and candidate genes for resistance to Fusarium ear rot and fumonisin contamination in maize. BMC Plant Biology 17: 20.

Maschietto, V., Lanubile, A., Leonardis, S.D., Marocco, A. and Paciolla, C., 2016. Constitutive expression of pathogenesis-related proteins and antioxydant enzyme activities triggers maize resistance towards Fusarium verticillioides. Journal of Plant Physiology 200: 53-61.

Mauro, A., Battilani, P., Callicott, K.A., Giorni, P., Pietri, A. and Cotty, P.J., 2013. Structure of an Aspergillus flavus population from maize kernels in northern Italy. International Journal of Food Microbiology 162: 1-7.

Mesterházy, Á., Lemmens, M. and Reid, L.M., 2012. Breeding for resistance to ear rots caused by Fusarium spp. in maize - a review. Plant Breeding 131: 1-19.

Morales, L., Marino, T.P., Wenndt, A.J., Fouts, J.Q., Holland, J.B. and Nelson, R.J., 2018. Dissecting symptomatology and fumonisin contamination produced by Fusarium verticillioides in maize ears. Phytopathology 108: 1475-1485.

Munkvold, G., 2003. Epidemiology of Fusarium diseases and their mycotoxins in maize ears. European Journal of Plant Pathology 109: 705-713.

Nielsen, R.L., Thomison, P.-R., Brown, G.A., Halter, A.L., Wells, J. and Wuethrich, K.L., 2002. Delayed planting effects on flowering and grain maturation of dent corn. Agronomy Journal 94: 549.

O’Brian, G.R., Georgianna, D.R., Wilkinson, J.R., Yu, J., Abbas, H.K., Bhatnagar, D., Cleveland, T.E., Nierman, W. and Payne, G.A., 2007. The effect of elevated temperature on gene transcription and aflatoxin biosynthesis. Mycologia 99: 232-239.

Okoth, S., Rose, L.J., Ouko, A., Netshifhefhe, N.E.I., Sila, H. and Viljoen, A., 2017. Assessing genotype by environment interactions in Aspergillus ear rot and preharvest aflatoxin accumulation in maize inbred lines. Agronomy 7: 86.
R Core Team, 2017. R: a language and environment for statistical computing. R Foundation for Statistical Computing, Vienna, Austria.

Reid, L.M., Zhu, X., Parker, A. and Yan, W., 2009. Increased resistance to Ustilago zeae and Fusarium verticillioides in maize inbred lines bred for Fusarium graminearum resistance. Euphytica 165: 567-578.

Robertson, L.A., Kleinschmidt, C.E., White, D.G., Payne, G.A., Maragos, C.M. and Holland, J.B., 2006. Heritabilities and correlations of Fusarium ear rot resistance and fumonisin contamination resistance in two maize populations. Crop Science 46: 353-361.

Robertson-Hoyt, L.A., Betrán, J., Payne, G.A., White, D.G., Isakeit, T., Maragos, C.M., Molnár, T.L. and Holland, J.B., 2007. Relationships among resistances to Fusarium and Aspergillus ear rots and contamination by fumonisin and aflatoxin in maize. Phytopathology 97: 311-317.

Rose, L.J., Okoth, S., Beukes, I., Ouko, A., Mouton, M., Flett, B.C., Makumbi, D. and Viljoen, A., 2017. Determining resistance to Fusarium verticillioides and fumonisin accumulation in maize inbred lines resistant to Aspergillus flavus and aflatoxins. Euphytica 213: 93.

Santiago, R., Cao, A. and Butrón, A., 2015. Genetic factors involved in fumonisin accumulation in maize kernels and their implications in maize agronomic management and breeding. Toxins 7: 3267-3296.

Scott, G.E. and Zummo, N., 1990. Registration of Mp313E parental line of maize. Crop Science 30: 1378.

Septiani, P., Lanubile, A., Stagnati, L., Busconi, M., Nelissen, H., Pè, M.E., Dell'Acqua, M. and Marocco, A., 2019. Unravelling the genetic basis of Fusarium seedling rot resistance in the MAGIC maize population: novel targets for breeding. Scientific Reports 9: 5665.

Stagnati, L., Lanubile, A., Samayoa, L.F., Bragalanti, M., Giorni, P., Busconi, M., Holland, J.B. and Marocco, A., 2019. A genome wide association study reveals markers and genes associated with resistance to Fusarium verticillioides infection of seedlings in a maize diversity panel. G3: Genes, Genomes, Genetics 9: 571-579.

Szabo, B., Toth, B., Toth Toldine, E., Varga, M., Kovacs, N., Varga, J., Kocsube, S., Palagyi, A., Bagi, F., Budakov, D., Stojšin, V., Lazić, S., Bodroža-Solarov, M., Čolović, R., Bekavac, G., Purar, B., Jocković, D. and Mesterházy, A., 2018. A new concept to secure food safety standards against Fusarium species and Aspergillus flavus and their toxins in maize. Toxins 10: 372.

Venables, W.N. and Ripley, B.D., 2002. Modern applied statistics with $S, 4^{\text {th }}$ edition. Springer, New York, NY, USA.

Warburton, M.L., Williams, W.P., Windham, G.L., Murray, S.C., Xu, W., Hawkins, L.K. and Duran, J.F., 2013. Phenotypic and genetic characterization of a maize association mapping panel developed for the identification of new sources of resistance to Aspergillus flavus and aflatoxin accumulation. Crop Science 53: 2374-2383.

Zila, C.T., Ogut, F., Romay, M.C., Gardner, C.A., Buckler, E.S. and Holland, J.B., 2014. Genome-wide association study of Fusarium ear rot disease in the U.S.A. maize inbred line collection. BMC Plant Biology 14: 372.

Zila, C.T., Samayoa, L.F., Santiago, R., Butrón, A. and Holland, J.B., 2013. A genome-wide association study reveals genes associated with Fusarium ear rot resistance in a maize core diversity panel. G3: Genes, Genomes, Genetics 3: 2095-2104.

Zuber, M.S., 1973. Registration of 20 maize parental lines. Crop Science 13: 779 . 
